\title{
Influence of pre-treatment methods on the adsorption of cadmium ions by chestnut shell
}

\author{
G. Vázquez, O. Mosquera, M. S. Freire, G. Antorrena \\ \& J. González-Álvarez \\ Department of Chemical Engineering, \\ University of Santiago de Compostela, Spain
}

\begin{abstract}
In this work the use of chestnut shell as an adsorbent of the cadmium ions present in some industrial wastewaters was studied. Various pre-treatments were performed to increase the sorption capacity of the material and simultaneously avoid the coloration of the water due to soluble polyphenols. The effect of the pre-treatments was evaluated using the pre-treated material to adsorb $\mathrm{Cd}^{2+}$ ions under specified conditions. The influence of the pre-treatment agent (water, sodium hydroxide, sulphuric acid, formaldehyde and sodium chloride) and of the operating conditions (temperature and time) on the sorption capacity of the pre-treated material was analysed using the pseudo-second order kinetic model. Equilibrium sorption capacities from 2.50 to $7.11 \mathrm{mg} \mathrm{Cd}^{2+} / \mathrm{g}$ oven-dried shell were achieved. The optimal results were obtained by pre-treating the shell with a $4 \% \mathrm{NaOH}$ aqueous solution for $24 \mathrm{~h}$ at room temperature. Under these conditions an adsorption percentage of $98.6 \%$ was obtained and $80 \%$ of the maximum sorption capacity was reached in less than $1 \mathrm{~h}$. X-ray photoelectron spectrometry (XPS) surface measurements were performed to compare the chemical composition of the pre-treated materials. Additionally, FTIR and XPS were used to analyze the functional groups involved in $\mathrm{Cd}$ binding.
\end{abstract}

Keywords: chestnut shell, adsorption, cadmium ions, pre-treatment, kinetic models, X-ray photoelectron spectrometry, Fourier transform infrared spectroscopy. 


\section{Introduction}

Activated carbons are the most effective and most used adsorbents; nevertheless, it is known that their high cost hinders their applicability and, in consequence, the investigations in the field of adsorption are centred in the search of new adsorbent materials that are widely available and of low cost, such as agricultural and industrial residues.

However, the application of untreated plant wastes as adsorbents can also bring several problems, such as low adsorption capacity, high chemical oxygen demand (COD) and biological chemical demand (BOD), as well as total organic carbon (TOC) due to the release of soluble organic compounds contained in the plant materials, which can cause depletion of oxygen content and threaten aquatic life. Therefore, some methods of pre-treatment have been used to increase the adsorption capacities of these adsorbents and to improve their performance [1].

The chestnut tree (Castanea sativa) takes up 46,000 ha and represents 5\% (in $\mathrm{m}^{3}$ with bark) of the total wood stock in Galicia (NW of Spain). Chestnut is a fruit whose exploitation has a great tradition in Galicia and around 8,000 t/year are processed in the food industry, where in the peeling process a waste product is produced, the chestnut shell.

In previous works of the authors [2-4], the removal of $\mathrm{Cd}^{2+}, \mathrm{Pb}^{2+}, \mathrm{Cu}^{2+}$ and $\mathrm{Zn}^{2+}$ ions from aqueous solutions by acid-formaldehyde pre-treated chestnut shell was studied. The results demonstrated the potential of this material for the removal of the above mentioned metal ions; however, the maximum adsorption capacities obtained under the conditions selected were quite low compared to those obtained with other bioadsorbents.

Hence, in order to increase the adsorption capacity of chestnut shell and decrease the release of water soluble phenolic compounds, the effect of different pre-treatments on cadmium adsorption was investigated. The influence of the pre-treatment agent (water, sodium hydroxide, sulphuric acid, formaldehyde and sodium chloride) and of the operating conditions (temperature and time) on the sorption capacity of the pre-treated chestnut shell was analysed using the pseudofirst and second-order kinetic models. Fourier transform infrared (FTIR) and Xray photoelectron (XPS) spectroscopies were used to characterize the pre-treated chestnut shells and metal speciation, respectively, and to identify the functional groups that participated in cadmium ions binding.

\section{Methods}

\subsection{Preparation and modification of the adsorbent}

Chestnut shell, supplied by a food factory (Marron Glacé, S.L., Ourense, NW of Spain), was air-dried till equilibrium moisture content (approximately, 18\% $\mathrm{w} / \mathrm{w}$ ), ground in a hammer mill and after classified, the fraction with particle sizes between 0.1 and $2 \mathrm{~mm}$ was selected. 
Table 1: $\quad$ Operational conditions for the different pre-treatments essayed.

\begin{tabular}{|c|c|c|c|c|}
\hline Pre-treatment & Agent & Concentration & $\begin{array}{c}\text { Temperature } \\
\left({ }^{\circ} \mathrm{C}\right)\end{array}$ & $\begin{array}{c}\text { Time } \\
(\mathrm{h})\end{array}$ \\
\hline P1 & Water & - & 25 & 24 \\
\hline P2 & $\mathrm{NaOH}$ & $4 \%(\mathrm{w} / \mathrm{w})$ & 25 & 24 \\
\hline P3 & Water & - & 90 & 4 \\
\hline P4 & $\mathrm{NaOH}$ & $4 \%(\mathrm{w} / \mathrm{w})$ & 90 & 4 \\
\hline P5 & $\mathrm{H}_{2} \mathrm{SO}_{4}$ & $50 \%(\mathrm{w} / \mathrm{w})$ & 25 & 4 \\
\hline P6 & $37 \% \mathrm{Formaldehyde}$ & $2 / 5(\mathrm{w} / \mathrm{v})$ & 50 & 2 \\
\hline P7 & $\mathrm{NaCl}$ & $30 \%(\mathrm{w} / \mathrm{w})$ & 25 & 24 \\
\hline
\end{tabular}

The pre-treatments were performed in a 2-L Pyrex glass reactor with mechanical stirring and temperature control. Water and different chemicals such as sodium hydroxide, sulphuric acid, formaldehyde and sodium chloride were used as modification agents at different conditions of time and temperature (Table 1).

Solid/liquid ratio was held constant at $1 / 10(\mathrm{w} / \mathrm{w})$, except for the acid formaldehyde treatment. For the pre-treatments at $25^{\circ} \mathrm{C}$, chestnut shell, water and the corresponding amount of chemical were mixed and the suspension was continuously stirred for the time selected. For the pre-treatments at $90^{\circ} \mathrm{C}$, chestnut shell and water were mixed at room temperature, heated and, in the case of P4 pre-treatment, once the selected temperature was attained the alkali was added and contact time begun to run. The acid formaldehyde pre-treatment was performed as follows [5]: to a mixture of $37 \%$ formaldehyde and $0.2 \mathrm{~N}$ sulphuric acid $(5 / 20, v / v)$, heated at $50^{\circ} \mathrm{C}$, the ground shell was added at a ratio of $2 / 5(\mathrm{~g}$ shell $/ \mathrm{mL}$ formaldehyde), and the suspension was stirred for $2 \mathrm{~h}$ in a water bath controlled at $50^{\circ} \mathrm{C}$.

For all pre-treatments once the selected time was elapsed, the suspension was vacuum filtered through a Büchner funnel and the solid residue was washed with distilled water until the $\mathrm{pH}$ of the filtrate was that of the washing water. The pretreated chestnut shell was oven-dried at $50^{\circ} \mathrm{C}$ for $24 \mathrm{~h}$. Drying at $50^{\circ} \mathrm{C}$ was chosen as higher drying temperatures could cause a decrease in the number of cellulose-based $\mathrm{OH}$ groups, provoking the thermal deactivation of the material surface [6].

\subsection{Batch adsorption experiments}

Cadmium solutions were prepared with ACS reagent grade $\mathrm{Cd}\left(\mathrm{NO}_{3}\right)_{2} .4 \mathrm{H}_{2} \mathrm{O}$. Adsorption experiments were carried out in a series of Erlenmeyer flasks covered with Parafilm ${ }^{\circledR}$ to prevent contamination. $100 \mathrm{~mL}$ of a cadmium ion solution of approximately $70 \mathrm{mg} / \mathrm{L}$ at their natural $\mathrm{pH}(5.5-6)$ were transferred to the flasks together with $1 \mathrm{~g}$ of pre-treated chestnut shell and placed in a water bath shaker maintained at $25^{\circ} \mathrm{C}$ and $90 \mathrm{rpm}$. At the time selected, the solution was filtered using glass microfibre filter paper and analysed for $\mathrm{pH}$ and residual $\mathrm{Cd}^{2+}$ ion concentrations by atomic absorption spectrometry. 
$\mathrm{pH}$ measurements were performed with a MP230 $\mathrm{pH}$ meter, which was standardized using buffer solutions of $\mathrm{pH}$ values of 4.00, 7.02 and 9.21.

GBC 932 AA atomic absorption spectrometer was used to analyse the initial and residual concentration of cadmium ions. Standard solutions for calibration were prepared using a cadmium standard solution of $1000 \mathrm{mg} / \mathrm{L}$ of cadmium nitrate in $0.5 \mathrm{M}$ nitric acid. Measurements were made in triplicate and those results in which the standard deviations were found beyond 95\% limit were not accepted.

\subsection{Adsorbent characterization}

FTIR spectra of natural shell, pre-treated shells and cadmium loaded shells were recorded by triplicate with a BRUKER IFS-66v spectrometer by the KBr pellet method, using a concentration of $2.5 \%$ ( $\mathrm{g}$ of sample/100 $\mathrm{g}$ of pellet).

$\mathrm{X}$-ray photoelectron spectra of milled pre-treated chestnut shell before and after $\mathrm{Cd}^{2+}$ ions adsorption were obtained with an X-ray photoelectron spectrometer (VG Scientific Escalaba 250 iXL ESCA instrument) using monochromatized Al Ka1,2 radiation (1486.92 eV). Measurements were done in a Constant Analyser Energy mode with $100 \mathrm{eV}$ pass energy for survey spectra and $20 \mathrm{eV}$ pass energy for high resolution spectra. Charge referencing was done by setting the lower binding energy $\mathrm{C} 1 \mathrm{~s}$ photopeak at the $285.0 \mathrm{eV} \mathrm{C} 1 \mathrm{~s}$ hydrocarbon peak. The spectra fitting based on Chi-squared algorithm was used to determine the goodness of a peak fit. Surface elemental composition was determined using the standard Scofield photoemission cross sections.

Prior to analysis, samples were finely ground using a ball mill and vacuum dried for a week. For each pre-treatment, the sample with the highest adsorption percentage was analysed.

\section{Results and discussion}

\subsection{Effect of chemical treatment on cadmium adsorption}

The time course profile of the cadmium adsorption process at $25^{\circ} \mathrm{C}$ for the different pre-treated chestnut shells is shown in figure 1 . The cadmium adsorbed percentage increased rapidly with time until the equilibrium was reached. The best results were obtained pre-treating the shell with a $4 \% \mathrm{NaOH}$ aqueous solution for $24 \mathrm{~h}$ at room temperature (P2 pre-treatment). Under these conditions, an equilibrium adsorption percentage of $98.6 \%$ was obtained and $80 \%$ of the maximum sorption capacity was reached in less than $1 \mathrm{~h}$. Pre-treatments with formaldehyde (P6) and sulphuric acid (P5) led to significantly lower adsorption percentages, with values at equilibrium of $41.1 \%$ and $38.5 \%$, respectively.

The equilibrium adsorption capacities of the pre-treated chestnut shells for cadmium ions, $\mathrm{q}_{\mathrm{e}}$ ( $\mathrm{mg}$ of $\mathrm{Cd}^{2+}$ adsorbed/g of chestnut shell) are compared in figure 2 . As previously mentioned, adsorption efficiency depended considerably on the type of modification applied, and values of the maximum adsorption capacity from 2.50 (for P6 pre-treatment) to $7.11 \mathrm{mg}$ of $\mathrm{Cd}^{2+} / \mathrm{g}$ of chestnut shell (for P2 pre-treatment) were achieved. 


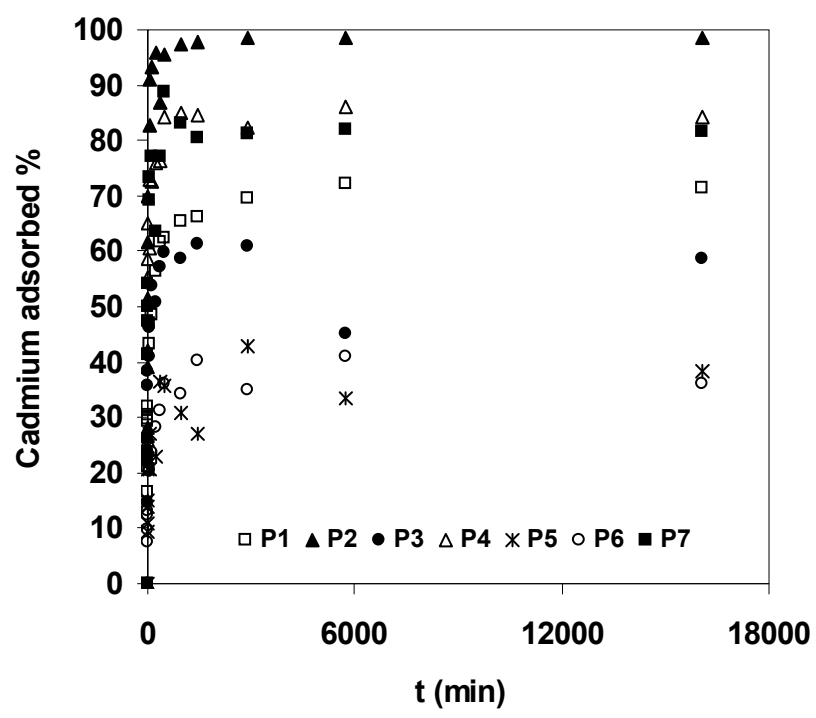

Figure 1: The effect of contact time on the cadmium adsorbed percentage by different pre-treated chestnut shells at $25^{\circ} \mathrm{C}$.

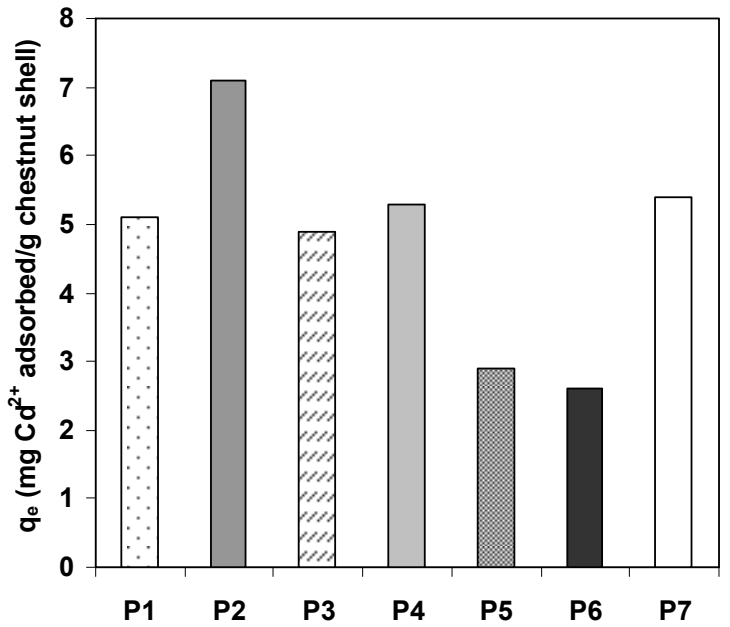

Figure 2: $\quad$ Efficiency of $\mathrm{Cd}^{2+}$ adsorption by the different pre-treated shells.

Adsorption capacities for $\mathrm{Cd}^{2+}$ ions of 7.1 and $5.3 \mathrm{mg} / \mathrm{g}$ were obtained when a $4 \%$ sodium hydroxide solution was used as pre-treatment agent at $25^{\circ} \mathrm{C}$ for $24 \mathrm{~h}$ (P2) and at $90^{\circ} \mathrm{C}$ for $4 \mathrm{~h}(\mathrm{P} 4)$, respectively, both higher that the value of $4.4 \mathrm{mg} / \mathrm{g}$ obtained in a previous work for an acid formaldehyde pre-treated chestnut shell [2]. Possibly, the alkali enhanced hydration, simultaneously extracted cell wall components and increased swelling, facilitating the adsorption of cadmium ions onto the chestnut shell surface [6]. Moreover, it's worth pointing out that there 
was an increase of the adsorption capacity of $20.5 \%$ when pre-treatment temperature was reduced from 90 to $25^{\circ} \mathrm{C}$.

Washing of chestnut shell with water (P1 and P3 pre-treatments) or its modification with a sodium chloride aqueous solution (P7) also enhanced the adsorption properties, whereas treatments with formaldehyde (P6) or sulphuric acid (P5) provided worse results for the adsorption efficiency.

\subsection{Kinetic modelling of cadmium adsorption}

Adsorption kinetics is an important aspect in the control of contaminant removal processes. The Lagergren's first-order kinetic and the Ho's pseudo-second order models, the most frequently used in literature to predict the mechanism involved in the adsorption process were applied to data in their integrated forms as given in eqns (1) and (2), respectively:

$$
\begin{gathered}
\ln \left(q_{e}-q_{t}\right)=\ln \left(q_{e}\right)-k_{1} t \\
\frac{t}{q_{t}}=\frac{1}{k_{2} q_{e}^{2}}+\frac{1}{q_{e}} \cdot t
\end{gathered}
$$

where $\mathrm{q}_{\mathrm{e}}$ and $\mathrm{q}_{\mathrm{t}}$ are the amounts of cadmium ions adsorbed onto the chestnut shell $(\mathrm{mg} / \mathrm{g})$, at the equilibrium and at time $\mathrm{t}$, respectively, $\mathrm{k}_{1}$ is the rate constant of the first order model $\left(\mathrm{min}^{-1}\right)$ and $\mathrm{k}_{2}$ is the second order adsorption rate constant $(\mathrm{g} / \mathrm{mg} \cdot \mathrm{min})$.

The pseudo first order model did not apply well throughout the whole range of contact times for any of the pre-treatments essayed and determination coefficients $\left(\mathrm{r}^{2}\right)$ lower than 0.7 were obtained. On the contrary, the pseudosecond-order kinetic model fitted well to the experimental data and good correlations between experimental and calculated data $\left(\mathrm{r}^{2}\right.$ higher than 0.99 and $\mathrm{p}<0.0001$ for a $95 \%$ of confidence level) were obtained. As an example, figure 3 demonstrates the high correlation obtained using the pseudo-second-order model for $\mathrm{Cd}^{2+}$ adsorption onto chestnut shell modified with a $4 \%$ sodium hydroxide

Table 2: Pseudo-second-order kinetic parameters and determination coefficients for the adsorption of $\mathrm{Cd}^{2+}$ on chestnut shell at an initial concentration of $70 \mathrm{mg} / \mathrm{L}$, natural $\mathrm{pH}$ and $25^{\circ} \mathrm{C}$.

\begin{tabular}{|c|c|c|c|}
\hline Pre-treatment & $\begin{array}{c}\mathrm{k}_{2} \\
(\mathrm{~g} / \mathrm{mg} \mathrm{min})\end{array}$ & $\begin{array}{c}\mathrm{q}_{\mathrm{e}} \\
(\mathrm{mg} / \mathrm{g})\end{array}$ & $\mathrm{r}^{2}$ \\
\hline P1 & $4.57 \cdot 10^{-3}$ & 5.05 & 0.999 \\
\hline P2 & $9.89 \cdot 10^{-3}$ & 7.11 & 1.000 \\
\hline P3 & $4.80 \cdot 10^{-3}$ & 4.53 & 0.991 \\
\hline P4 & $15.50 \cdot 10^{-3}$ & 5.26 & 0.999 \\
\hline P5 & $3.49 \cdot 10^{-3}$ & 2.90 & 0.996 \\
\hline P6 & $5.50 \cdot 10^{-3}$ & 2.50 & 0.997 \\
\hline P7 & $26.87 \cdot 10^{-3}$ & 5.37 & 1.000 \\
\hline
\end{tabular}




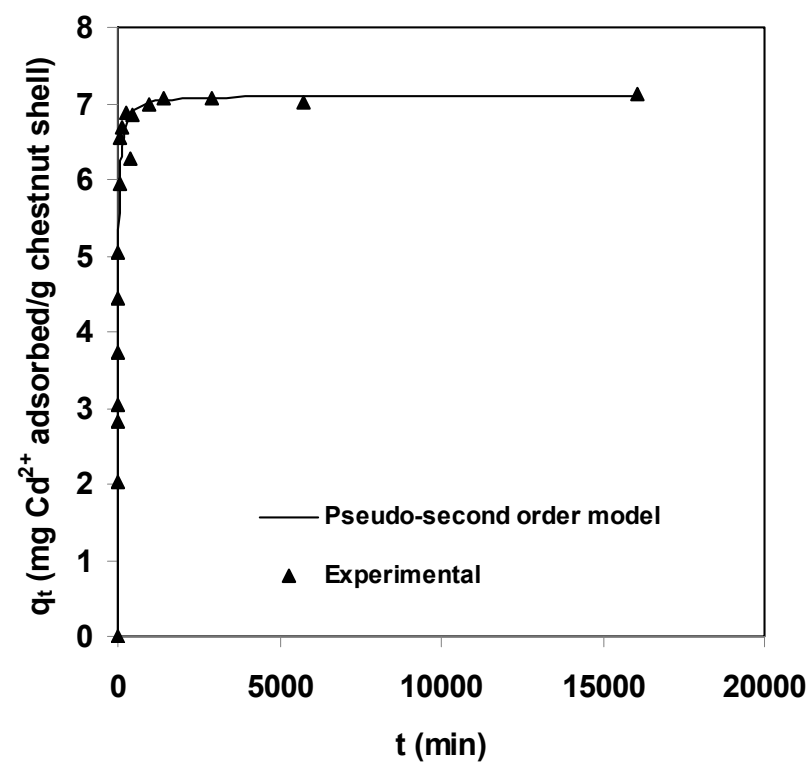

Figure 3: The effect of contact time on the adsorption of $\mathrm{Cd}^{2+}$ onto P2 pre-treated chestnut shell at $25^{\circ} \mathrm{C}$ and an initial concentration of $70 \mathrm{mg} / \mathrm{L}$. Experimental and calculated values by the pseudo-second order model.

aqueous solution at $25^{\circ} \mathrm{C}$ for $24 \mathrm{~h}(\mathrm{P} 2$ pre-treatment). The parameters of the model, $\mathrm{k}_{2}$ and $\mathrm{q}_{\mathrm{e}}$, and the corresponding determination coefficients are reported in table 2 .

\subsection{Characterization of the adsorbent before and after cadmium adsorption}

FTIR spectra of natural and modified chestnut shell revealed that all of them contained active groups (alcohols, aldehydes, ketones, phenolic hydroxides and ethers) of their constituent compounds (lignin, tannins, cellulose and hemicelluloses), which could interact with metal ions [7]. Moreover, spectra comparison demonstrated that the main functional groups found in natural chestnut shell remained unchanged after the different pre-treatments.

Additionally, FTIR spectra of the pre-treated chestnut shell before and after cadmium adsorption were used to analyse the changes in the vibrational frequency of the functional groups [2, 4]. In general, there were clear shifts and intensity changes of some bands, which increased or decreased depending on the pre-treatment applied. Thus, figure 4 shows, as an example, how the bands at $3000-3500 \mathrm{~cm}^{-1}$ (bonded $-\mathrm{OH}$ groups), $1606 \mathrm{~cm}^{-1}$ ( $\mathrm{C}=\mathrm{C}$ aromatic stretching), $1508 \mathrm{~cm}^{-1}\left(-\mathrm{NH}_{2}\right.$ groups) and $1024 \mathrm{~cm}^{-1}$ (C-O band in $-\mathrm{OCH}_{3}$ groups of the lignin) decreased after cadmium binding in $\mathrm{P} 2$ alkaline pre-treated chestnut shell. Similar changes were found for the shells with the higher adsorption capacities (P1, P3 and P7). 


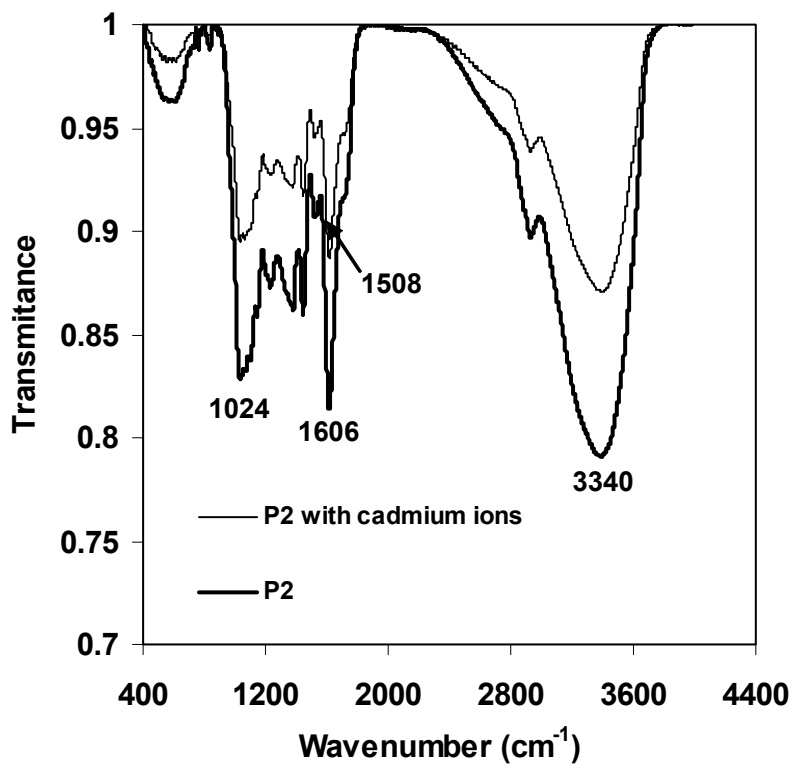

Figure 4: FTIR spectra of natural and cadmium loaded P2 pre-treated chestnut shell.

XPS was used to determine the interactions between the organic functional groups in the shell and the cadmium adsorbed. Table 3 summarizes the binding energies of the atoms and the changes in the atomic percentages (AT) between natural and cadmium-loaded pre-treated shells according to the XPS spectra.

Apart from the chestnut shell modified by P4, P6 and P7 pre-treatments, the atomic concentration of oxygen decreased after cadmium adsorption, especially for the alkaline pre-treated chestnut shell. These results provide evidence that the oxygen of carboxylic groups took part in cadmium adsorption [4], which is in good agreement with the FTIR results.

Figure 5 shows the binding energy profile of cadmium-loaded P2 pre-treated chestnut shell. The peaks at 406.2 and $413.0 \mathrm{eV}$, corresponding to $\mathrm{Cd}_{3 \mathrm{~d} 5 / 2}$ and $\mathrm{Cd}_{3 \mathrm{~d} 3 / 2}$, respectively, found in all XPS spectra of Cd-loaded pre-treated shells, demonstrated the presence of adsorbed $\mathrm{Cd}^{2+}$ on the shell surface.

\section{Conclusions}

Chestnut shell adsorption efficiency for cadmium ions was increased using different pre-treatments and was strongly dependent on the method used. The highest adsorption capacity and cadmium removal, $7.1 \mathrm{mg} / \mathrm{g}$ and $98.6 \%$, respectively, were achieved for the chestnut shell pre-treated with a $4 \%$ sodium hydroxide aqueous solution at $25^{\circ} \mathrm{C}$ for $24 \mathrm{~h}$. Pre-treatments with sodium chloride, water, sulphuric acid and formaldehyde led to lower and lower values 
Table 3: $\quad$ Peak numbers and atomic percentage (AT) of the atoms present in the XPS spectra of pre-treated chestnut shells before and after $\mathrm{Cd}^{2+}$ adsorption.

\begin{tabular}{|c|c|c|c|c|}
\hline Pre-treatment & Atom & \multicolumn{2}{|c|}{ Non-loaded } & Loaded \\
\hline & & Peak (eV) & AT $(\%)$ & AT $(\%)$ \\
\hline \multirow[t]{5}{*}{ P1 } & $\mathrm{C} 1 \mathrm{~s}$ & 285.00 & 68.8 & 66.6 \\
\hline & O1s & 532.5 & 28.0 & 27.8 \\
\hline & N1s & 399.0 & 1.3 & 1.4 \\
\hline & $\mathrm{Si} 2 \mathrm{p}$ & 102.0 & 0.9 & 2.2 \\
\hline & $\mathrm{Cd} 3 \mathrm{~d}$ & $\begin{array}{l}406.2(3 d 5 / 2) \\
413.0(3 d 3 / 2)\end{array}$ & - & 0.1 \\
\hline \multirow[t]{5}{*}{ P2 } & $\mathrm{C} 1 \mathrm{~s}$ & 285.00 & 70.2 & 76.2 \\
\hline & O1s & 532.5 & 26.9 & 20.7 \\
\hline & N1s & 399.0 & 1.4 & 1.0 \\
\hline & Si2p & 102.0 & 0.3 & 0.5 \\
\hline & $\mathrm{Cd} 3 \mathrm{~d}$ & $\begin{array}{l}406.2(3 d 5 / 2) \\
413.0(3 d 3 / 2)\end{array}$ & - & 0.1 \\
\hline \multirow[t]{5}{*}{ P3 } & $\mathrm{C} 1 \mathrm{~s}$ & 285.00 & 69.5 & 70.6 \\
\hline & O1s & 532.5 & 27.6 & 27.3 \\
\hline & N1s & 399.0 & 1.5 & 1.5 \\
\hline & Si2p & 102.0 & 0.7 & 0.3 \\
\hline & $\mathrm{Cd} 3 \mathrm{~d}$ & $\begin{array}{l}406.2(3 \mathrm{~d} 5 / 2) \\
413.0(3 \mathrm{~d} 3 / 2)\end{array}$ & - & 0.1 \\
\hline \multirow[t]{5}{*}{ P4 } & $\mathrm{C} 1 \mathrm{~s}$ & 285.00 & 80.9 & 68.2 \\
\hline & O1s & 532.5 & 18.0 & 28.8 \\
\hline & N1s & 399.0 & 1.1 & 1.6 \\
\hline & Si2p & 102.0 & - & 0.8 \\
\hline & $\mathrm{Cd} 3 \mathrm{~d}$ & $\begin{array}{l}406.2(3 \mathrm{~d} 5 / 2) \\
413.0(3 \mathrm{~d} 3 / 2)\end{array}$ & - & 0.2 \\
\hline \multirow[t]{5}{*}{ P5 } & $\mathrm{C} 1 \mathrm{~s}$ & 285.00 & 74.3 & 74.5 \\
\hline & O1s & 532.5 & 24.5 & 23.9 \\
\hline & N1s & 399.0 & 1.0 & 1.6 \\
\hline & Si2p & 102.0 & - & 0.8 \\
\hline & $\mathrm{Cd} 3 \mathrm{~d}$ & $\begin{array}{l}406.2(3 \mathrm{~d} 5 / 2) \\
413.0(3 \mathrm{~d} 3 / 2) \\
\end{array}$ & - & 0.2 \\
\hline \multirow[t]{5}{*}{ P6 } & $\mathrm{C} 1 \mathrm{~s}$ & 285.00 & 74.4 & 68.9 \\
\hline & O1s & 532.5 & 24.6 & 28.1 \\
\hline & N1s & 399.0 & 1.0 & 0.6 \\
\hline & Si2p & 102.0 & - & - \\
\hline & $\mathrm{Cd} 3 \mathrm{~d}$ & $\begin{array}{l}406.2(3 \mathrm{~d} 5 / 2) \\
413.0(3 \mathrm{~d} 3 / 2)\end{array}$ & - & - \\
\hline \multirow[t]{5}{*}{ P7 } & $\mathrm{C} 1 \mathrm{~s}$ & 285.00 & 71.5 & 64.2 \\
\hline & O1s & 532.5 & 27.2 & 31.3 \\
\hline & N1s & 399.0 & 1.3 & 1.3 \\
\hline & Si2p & 102.0 & & 0.2 \\
\hline & $\mathrm{Cd} 3 \mathrm{~d}$ & $\begin{array}{l}406.2(3 d 5 / 2) \\
413.0(3 d 3 / 2)\end{array}$ & & 0.1 \\
\hline
\end{tabular}




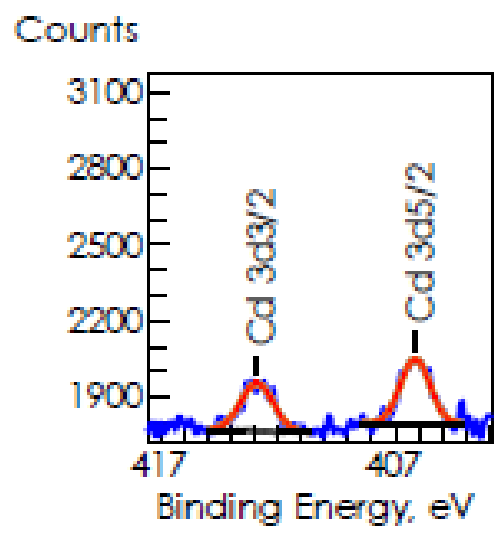

Figure 5: XPS spectra wide scan of cadmium-loaded pre-treated chestnut shell pre-treated with $4 \%$ sodium hydroxide aqueous solution at $25^{\circ} \mathrm{C}$ for $24 \mathrm{~h}$ (P2 treatment).

in that order. The pseudo-second order model was found suitable for describing batch adsorption of cadmium ions on all pre-treated chestnut shells. FTIR and XPS analysis revealed that some functional groups were involved in the cadmium adsorption.

\section{Acknowledgements}

This work was funded by Ministerio de Ciencia e Innovación, FEDER funds and Plan E funds (CTQ2009-07539)

\section{References}

[1] Ngah, W.S.W. \& Hanafiah, M.A.K.M., Removal of heavy metal ions from wastewater by chemically modified plant wastes as adsorbents: A review. Bioresource Technol., 99, pp. 3935-3948, 2008.

[2] Vázquez, G., Freire, M.S., González-Alvarez, J. \& Antorrena, G., Equilibrium and kinetic modelling of the adsorption of $\mathrm{Cd}^{2+}$ ions onto chestnut shell. Desalination, 249, pp. 855-860, 2009.

[3] Vázquez, G., González-Alvarez, J., Freire, M.S., Calvo, M. \& Antorrena, G., Determination of the optimal conditions for the adsorption of cadmium ions and phenol on chestnut (Castanea Sativa) shell. Global Nest J., 11(2), pp. 196-204, 2009.

[4] Vázquez, G., Calvo, M., Freire, M.S., González-Alvarez, J. \& Antorrena, G., Chestnut shell as heavy metal adsorbent: Optimization study of lead, copper and zinc cations removal. J. Hazard. Mater., 172, pp. 1402-1414, 2009.

[5] Vázquez, G., Antorrena, G., González, J. \& Doval, M.D., Adsorption of heavy metal ions by chemically modified Pinus pinaster bark. Bioresource Technol., 48, pp. 251-255, 1994. 
[6] Šćiban, M., Klašnja, M. \& Škrbić, B., Adsorption of copper ions from water by modified agricultural by-products. Desalination, 229, pp. 170-180, 2008.

[7] Argun, M.E., Dursun, S. \& Karatas, M., Removal of Cd(II), Pb(II), Cu(II) and Ni(II) from water using modified pine bark. Desalination, 249, pp. 519$527,2009$. 